\title{
Designing a brief behaviour change intervention to reduce sexually transmitted infections: a discrete choice experiment
}

\section{ABSTRACT}

Objectives: To understand whether people attending sexual health (SH) clinics are willing to participate in a brief behavioural change intervention $(\mathrm{BBCl})$ to reduce the likelihood of future sexually transmitted infections (STIS) and to understand their preferences for different service designs.

Methods: A discrete choice experiment (DCE) with young heterosexual adults (aged 1625 years), and men who have sex with men (MSM) aged 16 or above, attending SH clinics in England.

Results: Data from 368 participants showed that people particularly valued $\mathrm{BBCls}$ that involved talking (OR 1.45; 95\%Cl 1.35, 1.57 compared with an 'email or text' based $\mathrm{BBCl}$ ), preferably with a health care professional rather than a peer. Findings also showed that $26 \%$ of respondents preferred 'email / texts' to all other options; the remaining $14 \%$ preferred not to participate in any of the offered BBCls.

Implications: These results suggest that most people attending SH clinics in England are likely to participate in a $\mathrm{BBCl}$ if offered, but the type / format of the $\mathrm{BBCl}$ is likely to be the single important determinant of uptake rather than characteristics such as the length and the number of sessions. Moreover, participants generally favoured 'talking' based options rather than digital alternatives, which are likely to require the most resources to implement. Keywords

Sexually transmitted infections; health services; prevention; risk reduction; behaviour change; preferences; young people; men who have sex with men 


\section{INTRODUCTION}

Sexual behaviour is associated with a continuing and substantial burden of sexually transmitted infections (STIs), with 440,000 cases diagnosed in England, UK in 2014 [1]. The most commonly diagnosed STIs were chlamydia, genital warts, gonorrhoea and genital herpes (78\% of all infections). Moreover, the number of chlamydia cases has continued to increase over the past decade and gonorrhoea has become a particular concern as highly resistant infections are starting to emerge [1].

Young heterosexual adults (aged 16-25 years old) and men who have sex with men (MSM) remain the two groups at greatest risk of STIs in the UK [1]. The impact of this continued high number of new infections is significant in terms of individual health losses, an increased likelihood of further transmissions and costs to the National Health Service (NHS); around f620 million in 2011 excluding new HIV diagnoses [2].

The UK Department of Health's Sexual Health Framework has prioritised prevention and support for behavioural change interventions, alongside access to sexual and reproductive health services, particularly for those most vulnerable to poor sexual health [9]. Clinics that provide sexual health $(\mathrm{SH})$ services provide an opportunity to engage those at greatest likelihood of infection in sexual risk reduction interventions $[10,11]$ at a potentially teachable moment. Although challenging, introducing brief sexual risk reduction interventions into busy clinical settings on a large scale is essential if there is to be a population level impact. Indeed, the UK Government's White Paper 'Healthy Lives, Healthy People' emphasises a commitment to behaviour change interventions as a strategy to reduce preventable illness [3]. Research has shown they can help people adopt healthpromoting behaviour patterns, including safer sex practices $[4,5]$ and that many could be 
suited to SH clinic settings. However, of the interventions that are known to be acceptable and effective in changing risk and STI testing behaviours such as web-based applications and face-to-face counselling [6-8], it is unclear which are the most preferred and therefore most likely to be used [12].

This study is part of the SANTE project which aims to determine the feasibility of conducting a trial of brief behavioural change interventions ( $\mathrm{BBCl}$ 's) in SH services to reduce the incidence of STIs in young people and MSM [13]. A systematic review [8] of BBCI interventions suitable for use in SH settings identified a variety of effective interventions such as brief 1:1 counselling and web-based materials. The aims of the work are threefold. To determine the intervention characteristics, of those found effective, that are most likely to encourage people attending $\mathrm{SH}$ clinics to participate in a $\mathrm{BBCl}$ and the extent to which sociodemographic factors and previous STI testing / treatment are associated with potential use. A further aim was to identify changes to service characteristics that would cause people's BBCl preference to change.

\section{METHODS}

We assessed the potential uptake and preferences for different $\mathrm{BBCl}$ characteristics using a discrete choice experiment (DCE). DCEs are a method of estimating the relative strength of preference for different service options [14]. It is a hypothetical questionnaire approach that is often used when it is difficult to observe actual choices yet there is desire to understand drivers of consumer demand [15]. DCEs have a theoretical foundation in random utility theory, which is based on the assumptions of economic rationality and utility maximization [14]. In stating a preference, an individual is assumed to choose the option 
that produces the highest individual benefit (or 'utility'). Moreover, the utility generated by choosing an option is assumed to depend on the sum of the utilities associated with its composing attribute levels [16]. The results indicate the independent relative strength of preference for each defined service characteristic. Moreover, the preference scores can be combined to demonstrate if a theoretical service configuration is likely to be preferred, and therefore chosen, over others.

This DCE used a cross-sectional design in which participants were asked to choose between four competing $\mathrm{BBCls}$ or to indicate a preference not to participate with any of them (an 'opt out' option) (Table 1 and Figure 1) [17]. Each BBCl was described according to a number of key characteristics, such as who mediates the intervention, or the length of each session, referred to as 'attributes'. Each attribute had a number of 'levels', e.g. a 'nurse' or 'counsellor', which were rotated by scenario. Each participant was asked to complete 12 DCE questions.

\section{CHOICE OF BBCI OPTIONS, ATTRIBUTES AND LEVELS}

The $\mathrm{BBCl}$ options (labels), attributes and levels were informed by triangulation of data from the formative analysis, which included a qualitative study that explored patient and health care professionals' (HCP) perspectives of $\mathrm{BBCls}$ and a systematic literature review of $\mathrm{BBCls}$ feasible to deliver in SH settings (Figure 2) [8]. The qualitative study consisted of semistructured interviews with 15 men and women aged 16-25 years and 20 MSM who were aged 16 or above, who were recruited from London- and Brighton-based SH clinics and 
$26 \mathrm{SH}$ providers from across England. The systematic review identified 33 randomised controlled trials (RCTs) that included waiting-room-, self- and brief-healthcare providerdelivered interventions [8]. Interventions considered for inclusion had evidence supporting their effectiveness and were considered potentially feasible to implement given existing clinical service setups and resources in the UK.

The four BBCls included in the final design were 'talking' to someone (which was taken to denote talking therapies such as counselling and motivational interviewing), an 'email or text containing health advice', an 'online session by yourself' or an 'online group session' (see Table 1). The attributes included the type of contact, the type of activities involved in each session, the length and number of sessions and, where appropriate, the person who mediates the sessions. The number of sessions ( 1 to 6 ) and their length (up to 15 minutes to an hour) were deliberately kept short, as the remit was to investigate preferences for 'brief' behaviour change interventions.

\section{RECRUITMENT}

Participants were recruited from three SH clinics in Brighton and London, UK during November and December 2015 and were either heterosexual and aged between 16 and 25 years or a MSM and at least 16 years old, as they are the target groups specified for the project. No other inclusion or exclusion criteria were applied. Participants were recruited by researchers in the clinics, and asked to complete a paper-based version of the instrument. They were also asked to provide background information including educational status, 
previous STI testing history and previous STI diagnosis. All data were collected anonymously and written informed consent was obtained. In order to assess if our sample contained similar proportions of people in terms of age / sexual orientation , comparisons were made with GUMCADv2 data derived from the recruiting clinics[18]. London Westminster Research Ethics Committee granted ethical approval (REC reference 15/LO/0690).

\section{SAMPLE SIZE AND DCE QUESTIONNAIRE DESIGN}

Specifying sample sizes for DCE studies is difficult because the number of attributes, levels and choice sets is unknown in advance of designing the instrument. Orme, however, has suggested that a reasonable study size is around 300; we aimed to recruit 350 [19].

Twenty-four clinic attendees completed a pilot version of the questionnaire, which was generated using an orthogonal approach. The final design was generated using a D-efficient approach with priors from the pilot [17]. Eight versions of the questionnaire were produced in which the ordering of the DCE questions and options differed.

\section{STATISTICAL ANALYSIS}

All attribute levels were dummy-coded ( 1 for group membership, 0 otherwise) except when estimating the alternative specific constants (ASCs). These terms represent the extent to which people preferred one of the four $\mathrm{BBCl}$ options or opting out when all other factors are disregarded. Effects coding was used for the ASCs to avoid confounding with the attribute 
base levels on the main attributes [17]. 'Email or texts' was used as the reference option in all of the analyses.

\section{Assessing service and participant level characteristics associated with preferences}

The DCE responses were analysed using conditional logit (CLOGIT) and latent class models (LCM). The former is the basic form of analysis and identifies the relative preference of each attribute level but the results are presented for the average participant meaning it may mask important heterogeneities. LCMs also identify attribute level preferences but allow for heterogeneity by grouping respondents into classes that have similar preferences and identifying characteristics associated with probable class membership. [20] The class membership characteristics included in this analysis were selected on the basis of potential interest from a policy perspective and were: born in the UK (yes / no), previously diagnosed with an STI (yes / no), age / MSM status (categorised as heterosexual 16-20 years, heterosexual 21-25, MSM 16-25, MSM 26-50 and MSM 51+) and having tested for a STI within the past year (yes / no).

\section{Assessing how participants preferences for $\mathrm{BBCl}$ format might change if offered} alternative service configurations (simulations)

From a policy perspective, it is useful to understand if people's preferences, and therefore the likelihood they will engage with an intervention, can be changed by offering them different service options. To do this, a number of scenarios were generated using the LCM 
results to identify the service configurations that would be required for participants in each class to change away from their most preferred $\mathrm{BBCl}$ format to the next most valued option.

\section{RESULTS}

A total of 368 eligible people completed the questionnaire. Ninety percent (331/368) of respondents completed all 12 DCE questions, resulting in 21,495 DCE observations overall. Seventeen people only completed the first DCE question. Approximately $52 \%$ of responses were from Brighton, $59 \%$ were male and $62 \%$ were born in the UK (Table 2). Comparisons with the GUMCADv2 data suggested that our sample contained higher and lower proportions of MSM aged 16-25 and MSM aged 26-50 respectively but was similar in most other respects (Table 2 ).

Almost $20 \%$ of respondents (71/368) consistently chose one particular $\mathrm{BBCl}$ type, either the 'talking' (28/71) or email / text based options (34/71). There was minimal evidence to suggest that a particular attribute level dominated participants choices in so much that only a very small proportion of respondents always chose the option with the shortest duration (up to 15 minutes, $<1 \%$ ), the fewest number of session (one, $<1 \%$ ), sessions organised by nurses $(<1 \%)$ or by other HCPs $(<1 \%)$, whenever these options were presented. These findings provide some evidence that participants were willing to 'trade' between different $\mathrm{BBCl}$ design options, which is an important requirement of DCE studies if they are to be meaningful. 


\section{CLOGIT analysis to assess the preference for service characteristics}

The basic CLOGIT model was statistically significant, as it explained more of the variation in the data than a model with no independent variables (likelihood ratio chi-square test, $\mathrm{p}<0.0001$ ). McFadden's pseudo $\mathrm{R}^{2}$ was 0.13 , indicating that the model fitted the data moderately well [21] and predicted $41.7 \%(1,793 / 4,299)$ of choices correctly. The signs on the model coefficients were in a logical order demonstrating credibility in the underlying model. For example, people generally preferred shorter to longer sessions and a smaller to a larger number of sessions.

The results showed that participants generally preferred all BBCls formats to nothing ('opting out') but, 'talking' was clearly the most favoured option compared with 'email or texts' (OR 1.45; 95\% Cl 1.35, 1.57) (Figure 3). However, 'email and texts' were preferred to 'online group meetings' (OR 0.42; 95\%0.38, 0.47), 'online $1: 1$ meetings' (OR 0.44; 95\%0.39, 0.49 ) and to 'nothing' (OR $0.30 ; 95 \% 0.27,0.34)$.

'Face-to-face (F2F) group sessions' were generally less preferred to 'F2F 1:1 sessions (OR 0.66 ; $95 \% \mathrm{Cl}: 0.57,0.78$ ) or to ' $1: 1$ phone calls', although the latter comparison did not achieve statistical significance (OR $0.87 ; 95 \% \mathrm{Cl} 0.73,1.02$ ) (Figure 3 ). The analysis also showed that participants generally preferred fewer to more sessions, and shorter sessions were more highly valued than longer sessions. Additionally, the results indicated that participants had a strong preference for sessions to be facilitated by health counsellors rather than peers $(\mathrm{OR} 0.53 ; 95 \% \mathrm{Cl} 0.46,0.60)$, but they were indifferent about the type of 
health care professional (OR 1.02; 95\% $\mathrm{Cl} 0.90,1.15$ when health counsellors were compared to nurses).

Latent class model (LCM) to allow for heterogeneity in preferences and participant level predictors of it

The LCM predicted a higher proportion of correct choices than the CLOGIT analysis, 73\% $(2,419 / 3,312)$ (Figure 4). Three respondent classes were identified. Participants in each class were generally similar in how they valued the number / length of sessions, the choice of facilitator and whether or not meetings were one-to-one or group based. However, they differed markedly in terms of which general $\mathrm{BBCl}$ option they preferred. People who were more likely to be in class 1 (60\%) clearly favoured 'talking' interventions, although all other options were preferred to 'opting out'. Respondents who were more likely to be in class $2(14 \%)$ had a strong overall preference for 'opting out', although their next strongest preference was also for 'talking' interventions. Last, those more likely to be in class 3 (26\%) expressed a clear preference for 'email or text' based BBCls compared to all other options and were generally indifferent between the three remaining $\mathrm{BBCls}$ and 'opting out'. None of the sociodemographic variables included in the latent class analysis were predictive of likely class membership.

Simulations to identify how preferences for $\mathrm{BBCl}$ format could be changed by latent class Latent class group 1 
Participants in this class were only likely to prefer the online group or online 1:1 sessions (i.e. the next most favoured options) than 'talking' if each online session was much shorter (up to 15 minutes instead of between 30 and 60 minutes if 'talking'), the number of sessions was as small as possible (a one-off rather than repeated 'talking' sessions) and the 'talking' option was mediated by a peer rather than any other HCP. In all of the other configurations, the probability of people preferring, and therefore choosing, the 'talking' option remained the highest.

Latent class group 2

The likelihood of class 2 members choosing the 'talking-' instead of their generally preferred 'opt out-' option only occurred when it consisted of no more than three sessions, each lasting no longer than 30 minutes and when facilitated by a nurse or health counsellor, not a peer. The possibility of members of this class choosing any of the remaining $\mathrm{BBCls}$ options remained negligible in all of the remaining scenarios.

Latent class group 3

No scenarios were identified in which members of this class preferred anything other than the 'email / text' based option.

\section{DISCUSSION}


The study found that the uptake of BBCl's to prevent STIs could be high if offered to young heterosexual people and MSM attending UK SH clinics. However, it also suggests that the $\mathrm{BBCl}$ format (e.g. talking, emails / texts) is individually more likely to influence demand than factors such as the length and number of each session. Importantly, 'talking' was the most preferred $\mathrm{BBCl}$ format suggesting that personal interaction is important to people [22]. None of the assessed sociodemographic variables, such as a previous STI diagnosis, were found to predict choice suggesting, on the basis of these results alone, that there is no reason to tailor intervention formats for specific socioeconomic groups [22-24].

This research was commissioned as part of a project to determine the feasibility of conducting a randomised controlled trial of $\mathrm{BBCls}$. This was on the premise that a number of interventions have been shown to be effective but have not been implemented in a standardised or systematic way in the UKs National Health Service, or on a scale that could have a population level impact on STI diagnosis rates [8]. Further, the research brief was clear that any implementation would have to be provided with little or no additional resources being provided to SH services. In this context, identifying the characteristics of potential $\mathrm{BBCls}$ that result in high levels of acceptability is key. The strong preference for some form of intervention involving talking to a health care professional is therefore challenging. However, a number of scenarios were identified in which people who indicated a general preference for 'talking' based options instead preferred an online alternative. Moreover, there are also precedents for effective digital interventions being implemented to address public health needs, such as those to support smoking cessation [25] and problem alcohol consumption [26,27]. After initial investment, such interventions can be 
scaled up rapidly with little additional resources. An important determinant of success is ensuring the engagement of potential users, for which this DCE provides useful evidence. Indeed, the results suggest that for the majority of participants, the proposed BBCls were generally preferred over nothing at all. Thus, they are consistent with the strategy proposed in the SANTE project in which attendees at SH services would be offered a tailored package of BBCls, identified through the formative work, based on their risk of STIs [28].

It is difficult to compare the results of this DCE with those of existing studies. This is largely because other studies have either tended to assess levels of acceptability rather than preferences per se, evaluated a different set of prevention techniques (e.g condom use and microbicides) or did not focus on SH clinic attendees [29-31]. DCEs move beyond purely assessing acceptability, by generating estimates of the order and relative importance of intervention characteristics. This said however, interest is increasing in developing $\mathrm{BBCl}$ as digital interventions [32-34] particularly since the advent of social media, to potentially reach people who are not currently engaged with $\mathrm{SH}$ services and because they are considered to be comparatively cost efficient. While these studies have involved different types of online $\mathrm{BBCls}$ they have broadly demonstrated they are effective and acceptable to users $[29,35]$. Our results echo these findings in that they suggest online formats, while not the most preferred options, were preferred by most participants to being offered nothing at all. Together these results suggest that while those already in contact with $\mathrm{SH}$ services would prefer to use more resource intensive BBCls, this does not discount the possibility that a high uptake of appropriate digital interventions could be achieved. 
The strengths of this preference study were that it used a DCE design, which is more realistic than simply asking people what they prefer, and that it was underpinned by a systematic literature review [8] and a qualitative study to identify the $\mathrm{BBCl}$ formats and service characteristics. However, there were also a number of limitations with it. First, a number of options, such as having videos in clinics and distributing leaflets containing health advice, were excluded from the final DCE design. Videos were omitted on the basis that evidence from the other formative studies suggested that they were unlikely to be acceptable in a mixed clinic setting due to their content, and leaflets were seen as an adjunct to other interventions. Second, our focus was on establishing preferred $\mathrm{BBCl}$ characteristics, but they are clearly not the only type of intervention available for preventing STIs. For example, human papillomavirus vaccination [36] or HIV pre-exposure prophylaxis with antiretrovirals [37]. Finally, while there is evidence to show that results generated by DCEs correlate with actual choices [38] they still involve presenting participants with hypothetical choices so that their results should be taken as indicative of preferences rather than firm predictions of demand.

Fourteen percent of respondents (latent class 2 ) indicated that they would prefer not to participate in any of the $\mathrm{BBCl}$. The results indicate that shortening the length or number of the sessions and ensuring that, where applicable, they are one-to-one and mediated by HCPs, is unlikely to change their view, unless the 'talking' option is extremely brief and also facilitated by a health care professional rather than a peer. 
In summary, this DCE clearly indicates that most people attending SH clinics in England would be willing to engage with a $\mathrm{BBCl}$ if offered but that the choice of format is critical in ensuring maximum uptake. Most people appear to prefer talking based interventions, particularly when they are 1:1 with health care professionals. Although not generally the most preferred options, there does appear to be a role for email / text and digital BBCls, which are likely to be less costly to implement and easier to scale up. . However, the study does not suggest which $\mathrm{BBCl}$ is likely to be the most clinically- and cost-effective nor does it consider the content or the theoretical underpinning of the intervention [39]. 


\section{Compliance with Ethical Standards}

All the authors declare that they have no conflicts of interest.

Informed consent was obtained from all individual participants in the study. The London Westminster Research Ethics Committee (REC reference 15/LO/0690) gave ethical review and approval. 


\section{TABLES}

Table 1: The List of choices, attributes and levels and their applicability to each option

\begin{tabular}{|c|c|c|c|c|c|}
\hline \multirow[b]{2}{*}{ Attribute } & \multicolumn{5}{|c|}{ Options } \\
\hline & $\begin{array}{c}\text { Email or } \\
\text { text } \\
\text { containing } \\
\text { health } \\
\text { advice }^{\star}\end{array}$ & $\begin{array}{c}\text { Online } \\
\text { session by } \\
\text { yourself }\end{array}$ & $\begin{array}{l}\text { Online } \\
\text { group } \\
\text { session }\end{array}$ & $\begin{array}{l}\text { Talking with } \\
\text { at least one } \\
\text { person }\end{array}$ & Opt out \\
\hline $\begin{array}{l}\text { Type of } \\
\text { contact }\end{array}$ & $\begin{array}{c}\text { Emails or } \\
\text { texts from a } \\
\text { NHS service } \\
\text { containing } \\
\text { health } \\
\text { information }\end{array}$ & $\begin{array}{l}\text { Interactive } \\
\text { online } \\
\text { information } \\
\text { including } \\
\text { videos and } \\
\text { quizzes }\end{array}$ & $\begin{array}{l}\text { A Facebook } \\
\text { Group Chat or } \\
\text { Twitter (or } \\
\text { similar online } \\
\text { social media) }\end{array}$ & $\begin{array}{c}\text { A } 1: 1 \text { phone } \\
\text { conversation, } \\
1: 1 \text { face-to- } \\
\text { face meeting } \\
\text { at a clinic or } \\
\text { group face- } \\
\text { to-face } \\
\text { meeting at a } \\
\text { clinic }\end{array}$ & $\mathrm{N} / \mathrm{a}$ \\
\hline $\begin{array}{l}\text { Type of } \\
\text { session }\end{array}$ & $\begin{array}{l}\text { Reading } \\
\text { emails / texts }\end{array}$ & $\begin{array}{l}\text { Typing } \\
\text { questions and } \\
\text { responses }\end{array}$ & $\begin{array}{c}\text { Read / } \\
\text { watching } \\
\text { online and } \\
\text { ticking boxes } \\
\text { via a web } \\
\text { page or app }\end{array}$ & Talking & $\mathrm{N} / \mathrm{a}$ \\
\hline $\begin{array}{l}\text { Length of } \\
\text { each } \\
\text { sessions }\end{array}$ & $\mathrm{N} / \mathrm{a}$ & $\begin{array}{l}\text { Up to } 15^{\wedge}, 30 \\
\text { or } 60 \text { mins }\end{array}$ & $\begin{array}{l}\text { Up to } 15^{\wedge}, 30 \\
\text { or } 60 \text { mins }\end{array}$ & $\begin{array}{l}\text { Up to } 15^{\wedge}, 30 \\
\text { or } 60 \text { mins }\end{array}$ & $\mathrm{N} / \mathrm{a}$ \\
\hline $\begin{array}{l}\text { Number of } \\
\text { sessions }\end{array}$ & $\mathrm{N} / \mathrm{a}$ & $1^{\wedge}, 2-3$ or $4-6$ & $1^{\wedge}, 2-3$ or $4-6$ & $1^{\wedge}, 2-3$ or $4-6$ & $\mathrm{~N} / \mathrm{a}$ \\
\hline $\begin{array}{l}\text { The person } \\
\text { who } \\
\text { mediates the } \\
\text { sessions }\end{array}$ & $\mathrm{N} / \mathrm{a}$ & $\mathrm{N} / \mathrm{a}$ & $\begin{array}{c}\text { A health } \\
\text { counsellor } \\
\text { nurse or peer }\end{array}$ & $\begin{array}{c}\text { A health } \\
\text { counsellor } \\
\text { nurse or peer }\end{array}$ & $\mathrm{N} / \mathrm{a}$ \\
\hline
\end{tabular}

${ }^{*}$ the base option for the reported odds ratios; ${ }^{\wedge}$ the base level for each attribute; N/a, not applicable 


\begin{tabular}{|c|c|c|}
\hline & Respondents & GUMCADv2 data^ \\
\hline & $\mathbf{N}(\%)$ & $\mathbf{N}(\%)$ \\
\hline \multicolumn{3}{|l|}{ Recruitment location } \\
\hline Brighton & $191(52.0)$ & - \\
\hline London & $177(48.0)$ & - \\
\hline \multicolumn{3}{|l|}{ Born } \\
\hline UK & 229 (62.2) & - \\
\hline Outside UK & $114(40.0)$ & - \\
\hline Missing & $25(6.8)$ & - \\
\hline \multicolumn{3}{|l|}{ Gender } \\
\hline Male & $217(59.0)$ & - \\
\hline Female & $145(39.4)$ & - \\
\hline Transgender & $6(1.6)$ & - \\
\hline Missing & $0(0)$ & - \\
\hline
\end{tabular}

Age / gender group (years)*

$\begin{array}{lcc}\text { Heterosexual 16-20 } & 67(18.2) & 4,025(17.4) \\ \text { Heterosexual 21-25 } & 116(31.5) & 8,474(36.4) \\ \text { MSM 16-25 } & 42(11.4) & 1,355(5.8) \\ \text { MSM 26-50 } & 92(25.0) & 7,222(31.0) \\ \text { MSM 50+ } & 24(6.5) & 2,190(9.4) \\ \text { Missing } & 27(7.3) & \end{array}$

Previously diagnosed STI

$\begin{array}{lc}\text { Yes } & 169(45.9) \\ \text { No } & 169(45.9) \\ \text { Missing } & 30(8.2)\end{array}$

STI tests in previous year

$\begin{array}{lc}0 & 80(21.7) \\ 1 & 106(28.8) \\ 2 & 83(22.6) \\ 3+ & 81(22.0) \\ \text { Missing } & 18(4.9)\end{array}$

^Data taken from GUMCADv2 2015 data [18]; chi ${ }^{2}$ test performed on non-missing data, $p<0.0001$ 


\section{Figure Headings}

Figure 1: Example of a DCE question

Figure 2: DCE design and analysis flow chart (suggested Web extra)

Figure 3: Results from the conditional logistic (CLOGIT) regression model

Figure 4: Latent class model results 


\section{REFERENCES}

1. Public Health England: Infection report volume 9 number 22.

https://www.gov.uk/government/uploads/system/uploads/attachment data/file/437433/h pr2215 STI NCSP v6.pdf (2015). Accessed 22/06/2017

2. Development Economics: Unprotected nation: the financial and economic impacts of restricted contraceptive and sexual health services.

http://www.fpa.org.uk/sites/default/files/unprotected-nation-sexual-health-full-report.pdf (2013). Accessed 26/04/2017

3. Department of Health: Healthy lives, healthy people: our strategy for public health in England. https://www.gov.uk/government/uploads/system/uploads/attachment data/file/216096/d h 127424.pdf (2010). Accessed 26/04/2017

4. Johnson, B.T., Carey, M.P., Marsh, K.L., Levin, K.D., Scott-Sheldon, L.A.: Interventions to reduce sexual risk for the human immunodeficiency virus in adolescents, 1985-2000: a research synthesis. Arch Pediatr Adolesc Med 157(4), 381-388 (2003). doi:10.1001/archpedi.157.4.381

5. Kalichman, S.C., Carey, M.P., Johnson, B.T.: Prevention of sexually transmitted HIV infection: A meta-analytic review of the behavioral outcome literature. Annals of behavioral medicine : a publication of the Society of Behavioral Medicine 18(1), 6-15 (1996). doi:10.1007/bf02903934

6. Albarracin, D., Gillette, J.C., Earl, A.N., Glasman, L.R., Durantini, M.R., Ho, M.H.: A test of major assumptions about behavior change: a comprehensive look at the effects of passive and active HIV-prevention interventions since the beginning of the epidemic. Psychological bulletin 131(6), 856-897 (2005). doi:10.1037/0033-2909.131.6.856

7. Johnson, B.T., Scott-Sheldon, L.A., Carey, M.P.: Meta-synthesis of health behavior change metaanalyses. Am J Public Health 100(11), 2193-2198 (2010). doi:10.2105/ajph.2008.155200

8. Long, L., Abraham, C., Paquette, R., Shamanesh, M., Llewellyn, C., Townsend, A.: Brief In-service interventions to prevent sexually transmitted infections: a systematic review. Preventative Medicine 91, 364-382 (2016).

9. Department of Health: A framework for sexual health improvement in England. https://www.gov.uk/government/publications/a-framework-for-sexual-healthimprovement-in-england (2013). Accessed 26/04/2017

10. Cook, R.L., Comer, D.M., Wiesenfeld, H.C., Chang, C.-C.H., Tarter, R., Lave, J.R., Clark, D.B.: Alcohol and Drug Use and Related Disorders: An Underrecognized Health Issue Among Adolescents and Young Adults Attending Sexually Transmitted Disease Clinics. Sexually Transmitted Diseases 33(9), 565-570 (2006). doi:10.1097/01.olq.0000206422.40319.54

11. Howards, P.P., Thomas, J.C., Earp, J.A.: Do clinic-based STD data reflect community patterns? Int J STD AIDS 13(11), 775-780 (2002). doi:10.1258/095646202320753745

12. Glasgow, R.E., Bull, S.S., Gillette, C., Klesges, L.M., Dzewaltowski, D.A.: Behavior change intervention research in healthcare settings: a review of recent reports with emphasis on external validity. American journal of preventive medicine 23(1), 62-69 (2002).

13. Gilson, R., Llewellyn, C., Shahmanesh, M., Abraham, C., Mercer, C.H., Hughes, G., Copas, A., Miners, A., Bailey, J., Rodger, A., Burns, F., Mann, S., Richardson, D., Clark, L.: Sexual risk reduction interventions for patients attending sexual health clinics; feasibility to conduct an effectiveness trial. Study protocol version 1.0.

https://www.journalslibrary.nihr.ac.uk/programmes/hta/1219105\#/ (2014). Accessed 26/04/2017

14. Ryan, M.: Discrete choice experiments in health care. BMJ 328(7436), 360-361 (2004). doi:10.1136/bmj.328.7436.360 
15. Mangham, L.J., Hanson, K., McPake, B.: How to do (or not to do) ... Designing a discrete choice experiment for application in a low-income country. Health Policy and Planning 24(2), 151158 (2009). doi:10.1093/heapol/czn047

16. Lancaster, K.: A new approach to consumer theory. Journal of Political Economy 74, 132-157 (1966).

17. ChoiceMetrics: Ngene 1.1.2 User manual and reference guide. Version 15/07/2014. In. (2014)

18. Public Health England: Genitourinary medicine clinic activity dataset (GUMCADv2). https://www.gov.uk/guidance/genitourinary-medicine-clinic-activity-dataset-gumcadv2. Accessed 21/07/2016

19. Orme, B.: Sample size issues for conjoint analysis. http://www.sawtoothsoftware.com/download/techpap/samplesz.pdf (2010). Accessed 26/04/2017

20. Lagarde, M., Erens, B., Mays, N.: Determinants of the choice of GP practice registration in England: Evidence from a discrete choice experiment. Health Policy 119, 427-436 (2015). doi:http://dx.doi.org/10.1016/j.healthpol.2014.10.008

21. Hauber, A.B., Gonzalez, J.M., Groothuis-Oudshoorn, C.G., Prior, T., Marshall, D.A., Cunningham, C., MJ, I.J., Bridges, J.F.: Statistical Methods for the Analysis of Discrete Choice Experiments: A Report of the ISPOR Conjoint Analysis Good Research Practices Task Force. Value in Health 19(4), 300-315 (2016). doi:10.1016/j.jval.2016.04.004

22. Rietmeijer, C.A.: Risk reduction counselling for prevention of sexually transmitted infections: how it works and how to make it work. Sexually Transmitted Infections 83(1), 2-9 (2007). doi:10.1136/sti.2006.017319

23. National Institute for Health and Care Excellence: Sexually transmitted infections and under-18 conceptions: prevention. https://www.nice.org.uk/guidance/ph3/resources/sexuallytransmitted-infections-and-under18-conceptions-prevention-55452476869 (2007). Accessed 26/04/2017

24. National Institute for Health and Care Excellence: HIV testing: increasinguptake among people who may have undiagnosed HIV. (2016). 27/04/2017

25. Free, C., Knight, R., Robertson, S., Whittaker, R., Edwards, P., Zhou, W., Rodgers, A., Cairns, J., Kenward, M.G., Roberts, I.: Smoking cessation support delivered via mobile phone text messaging (txt2stop): a single-blind, randomised trial. The Lancet 378(9785), 49-55. doi:http://dx.doi.org/10.1016/S0140-6736(11)60701-0

26. Carra, G., Crocamo, C., Bartoli, F., Carretta, D., Schivalocchi, A., Bebbington, P.E., Clerici, M.: Impact of a Mobile E-Health Intervention on Binge Drinking in Young People: The DigitalAlcohol Risk Alertness Notifying Network for Adolescents and Young Adults Project. The Journal of adolescent health : official publication of the Society for Adolescent Medicine 58(5), 520-526 (2016). doi:10.1016/j.jadohealth.2016.01.008

27. Champion, K.E., Newton, N.C., Teesson, M.: Prevention of alcohol and other drug use and related harm in the digital age: what does the evidence tell us? Current opinion in psychiatry 29(4), 242-249 (2016). doi:10.1097/yco.0000000000000258

28. Gilson, R., Shahmanesh, M., Abraham, C., Mercer, C., Hughes, G., Copas, A., Miners, A., Bailey, J., Rodger, A., Burns, F., Mann, S., Richardson, D., Clark, L.: Sexual health risk reduction interventions - the Sante Project.

http://www.nets.nihr.ac.uk/ data/assets/pdf file/0005/130667/PRO-12-191-05.pdf (2014). Accessed 30/06/2016

29. French, R.S., McCarthy, O., Baraitser, P., Wellings, K., Bailey, J.V., Free, C.: Young People's Views and Experiences of a Mobile Phone Texting Intervention to Promote Safer Sex Behavior. JMIR research protocols 4(2), e26 (2016). doi:10.2196/mhealth.4302

30. Pachankis, J.E., Lelutiu-Weinberger, C., Golub, S.A., Parsons, J.T.: Developing an Online Health Intervention for Young Gay and Bisexual Men. AIDS and behavior 17(9), 2986-2998 (2013). doi:10.1007/s10461-013-0499-8 
31. Terris-Prestholt, F., Hanson, K., MacPhail, C., Vickerman, P., Rees, H., Watts, C.: How Much Demand for New HIV Prevention Technologies Can We Really Expect? Results from a Discrete Choice Experiment in South Africa. PLoS ONE 8(12), e83193 (2013). doi:10.1371/journal.pone.0083193

32. Lelutiu-Weinberger, C., Pachankis, J.E., Gamarel, K.E., Surace, A., Golub, S.A., Parsons, J.T.: Feasibility, Acceptability, and Preliminary Efficacy of a Live-Chat Social Media Intervention to Reduce HIV Risk Among Young Men Who Have Sex With Men. AIDS and behavior 19(7), 1214-1227 (2015). doi:10.1007/s10461-014-0911-z

33. Mustanski, B., Garofalo, R., Monahan, C., Gratzer, B., Andrews, R.: Feasibility, acceptability, and preliminary efficacy of an online HIV prevention program for diverse young men who have sex with men: the keep it up! intervention. AIDS and behavior 17(9), 2999-3012 (2013). doi:10.1007/s10461-013-0507-z

34. Bailey, J., Mann, S., Wayal, S., Hunter, R., Free, C., Abraham, C., Murray, E.: Public Health Research. In: Sexual health promotion for young people delivered via digital media: a scoping review. NIHR Journals Library, Southampton (UK) (2015)

35. Swendeman, D., Rotheram-Borus, M.J.: Innovation in sexually transmitted disease and HIV prevention: internet and mobile phone delivery vehicles for global diffusion. Current opinion in psychiatry 23(2), 139-144 (2010). doi:10.1097/YCO.0b013e328336656a

36. Palefsky , J.M., Giuliano , A.R., Goldstone , S., Moreira , E.D.J., Aranda , C., Jessen , H., Hillman , R., Ferris , D., Coutlee , F., Stoler , M.H., Marshall , J.B., Radley , D., Vuocolo , S., Haupt , R.M., Guris, D., Garner , E.I.O.: HPV Vaccine against Anal HPV Infection and Anal Intraepithelial Neoplasia. New England Journal of Medicine 365(17), 1576-1585 (2011). doi:doi:10.1056/NEJMoa1010971

37. McCormack, S., Dunn, D.T., Desai, M., Dolling, D.I., Gafos, M., Gilson, R., Sullivan, A.K., Clarke, A., Reeves, I., Schembri, G., Mackie, N., Bowman, C., Lacey, C.J., Apea, V., Brady, M., Fox, J., Taylor, S., Antonucci, S., Khoo, S.H., Rooney, J., Nardone, A., Fisher, M., McOwan, A., Phillips, A.N., Johnson, A.M., Gazzard, B., Gill, O.N.: Pre-exposure prophylaxis to prevent the acquisition of HIV-1 infection (PROUD): effectiveness results from the pilot phase of a pragmatic open-label randomised trial. The Lancet 387(10013), 53-60. doi:10.1016/S01406736(15)00056-2

38. Lancsar, E., Swait, J.: Reconceptualising the external validity of discrete choice experiments. Pharmacoeconomics 32(10), 951-965 (2014). doi:10.1007/s40273-014-0181-7

39. Abraham, C., Kelly, M.P., West, R., Michie, S.: The UK National Institute for Health and Clinical Excellence public health guidance on behaviour change: a brief introduction. Psychol Health Med 14(1), 1-8 (2009). doi:10.1080/13548500802537903 